
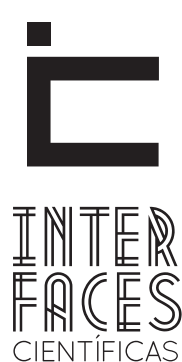

HUMANAS E SOCIAIS

ISSN IMPRESSO 2316-3348

E-ISSN 2316-3801

DOI - 10.17564/2316-3801.2018v7n1p137-148

\title{
ATIVIDADES SUJEITAS AO LICENCIAMENTO AMBIENTAL E SUAS CONTROVÉRSIAS
}

\author{
ACTIVITIES SUBJECT TO ENVIRONMENTAL LICENSING AND ITS CONTROVERSIES \\ ACTIVIDADES SUJETAS AL LICENCIAMIENTO AMBIENTAL Y SUS CONTROVERSIAS
}

Franciele Faistel ${ }^{1}$

Adauto Ribeiro de Souza²

Maria José Nascimento Soares ${ }^{3}$

\section{RESUMO}

A defesa do meio ambiente é um dever de todos, está estabelecida em lei, sua base legal encontra-se disposta no caput do art. 225 da CF/88 entre outras. Uma das formas de proteção do meio ambiente é a limitação na operação de atividades e empreendimentos que possam causar danos ao meio ambiente, por meio do chamado licenciamento ambiental. Este é um importante instrumento, previsto tanto na Magna Carta como na Política Nacional do Meio ambiente e Resoluções do Conselho Nacional do Meio Ambiente (CONAMA). As atividades sujeitas ao licenciamento ambiental geram amplo debate a respeito da classificação apresentada no Anexo 1 da Resolução 237/97 por tratar-se de um rol exemplificativo. Outra controversa é a questão da competência para o licenciamento, a cargo dos órgãos ambientais brasileiros, que serão apresentados neste artigo científico.

\section{PALAVRAS-CHAVE}

Licenciamento Ambiental. Atividades Poluidoras. Resolução CONAMA 237/97. 


\section{ABSTRACT}

The defense of the environment a duty of all, is established in law, its legal basis is set out in the caput of art. 225 of CF / 88 and others. One of the ways of protecting the environment is the limitation in the operation of activities and under takings that may cause damage to the environment, through so called environmental licensing. This is an important instrument, foreseen both in the Magna Carta (Brazilian Constitution) and in the National Policy on the Environment and Resolutions (CONAMA). The activities subject to environmental licensing generate a wide debate regarding the classification presented in Annex 1 of Resolution $237 / 97$ as it is an exemplary role. Another controversial issue is the competence for licensing, by the Brazilian environmental agencies, which will be presented in this scientific article.

\section{KEYWORDS}

Environmental Licensing. Polluting Activities. Resolution CONAMA 237/97.

\section{RESUMEN}

La defensa del medio ambiente es un deber de todos, está establecida en ley, su base legal se encuentra dispuesta en el caput del art. 225 de la CF / 88 entre otras. Una de las formas de protección del medio ambiente es la limitación en la operación de actividades y emprendimientos que puedan causar daños al medio ambiente, a través del llamado licenciamiento ambiental. Este es un importante instrumento, previsto tanto en la Magna Carta como en la Política Nacional del Medio Ambiente y Resoluciones CONAMA. Las actividades sujetas al licenciamiento ambiental generan amplio debate sobre la clasificación presentada en el Anexo 1 de la Resolución 237/97 por tratarse de un ejemplar. Otra controversia es la cuestión de la competencia para el licenciamiento, a cargo de los órganos ambientales brasileños, que serán presentados en este artículo científico.

\section{PALABRAS CLAVE}

Licencias ambientales. Actividades contaminantes. Resolución CONAMA 237/97. 


\section{INTRODUÇÃ̃O}

Após leitura sobre as diversas escritas de juristas, ambientalistas, economistas, entre outros, fica evidente a importância do licenciamento ambiental como principal ferramenta da Política Nacional do Meio Ambiente, classificado inclusive como instrumento econômico ambiental, devido ao fato de autorizar ou não atividades e empreendimentos de modo efetivo que por sua vez potencialmente causa impacto ambiental ao utilizar recursos naturais.

Percebe-se, portanto, que determinadas atividades ou empreendimentos possuem impactos ambientais efetivos e se utilizam de recursos naturais em abundância, estes por sua vez são considerados bens públicos, pertencentes à coletividade. Em determinados casos, a exploração de alguns recursos (calcário, ferro, petróleo, ouro, alumínio, estanho), são explorados na esfera privada e o impacto ambiental acaba sendo coletivo.

Nesta perspectiva, o licenciamento ambiental possui uma importante função na proteção do meio ambiente, na medida em que autoriza atividades que exploram o meio ambiente por meio de condicionantes para minimizar os impactos ambientais.

\section{LICENCIAMENTO AMBIENTAL COMO INSTRU- MENTO DE PROTEÇÃO DO MEIO AMBIENTE}

O licenciamento ambiental criado com a finalidade de expedir licenças para atividades ou empreendimentos com significativo impacto ambiental e/ ou utilizadoras de recursos naturais, foi um recurso/ instrumento criado na década de 1980, em âmbito nacional, pois a Política Nacional do Meio Ambiente (PNMA) data de 1981, a qual prevê o licenciamento como instrumento dessa Política.

Neste período, o cenário ambiental era outro, ou seja, não é o apresentado nos dias atuais, o que requer uma análise aprofundada e detalhada da efeti- vidade deste instrumento ambiental na sua prática. Araújo (2013, p. 25) destaca que:

\begin{abstract}
O Licenciamento Ambiental é um dos mais importantes instrumentos de gestão do meio ambiente, posto que, através dele, a Administração Pública efetivará o controle prévio das atividades econômicas utilizadoras de recursos ambientais e potencialmente degradadoras, impondo condições e medidas de controle ambiental ao empreendedor, a fim de que este adéque sua atividade, obra, empreendimento ou serviço às normas de tutela ambiental, evitando, minimizando ou compensando danos ao meio ambiente e à sadia qualidade de vida e saúde da coletividade.
\end{abstract}

Desse modo, o licenciamento ambiental é considerado por alguns doutrinadores, como o principal instrumento da Política Nacional do Meio Ambiente, Lei no $6.938 / 81$ e o princípio do desenvolvimento sustentável está diretamente ligado ao tema como afirma Sarlet e Fenterseifer (2014, p. 94) que o licenciamento

\begin{abstract}
[...] destaca-se, entre outros instrumentos jurídicos criados com o propósito de conciliar as práticas produtivas com a proteção ambiental, o estudo prévio de impacto ambiental (art.225, §1, IV, da CF/88, art.10 da Lei n.6.938/81 e Resolução CONAMA) exigido para a instalação de obra ou atividade causadora de significativa degradação ambiental. Em linhas gerais, trata-se de um mecanismo jurídico de ajuste e regulação da atividade econômica, que limita o direito de propriedade e a livre-iniciativa dos atores econômicos privados, conformando o seu comportamento ao princípio constitucional (e dever) do desenvolvimento sustentável.
\end{abstract}

A partir da Resolução 237/97, que apresentou novas diretrizes para o licenciamento ambiental, na medida que este representa um instrumento importante para a política Nacional do Meio Ambiente, estabelece-se uma nova discussão teórica sendo que a prática muitas vezes é esquecida, qual seja: de como conciliar desenvolvimento econômico com preservação ambiental. Ambos atualmente são indispensáveis para a sociedade global.

Fiorillo (2015, p. 245) observa que o licenciamento ambiental é uma atividade administrativa ambiental fundamental para a preservação do meio ambiente e 
que se utiliza dos seguintes estudos ambientais: $\mathrm{AlA}^{4}$, $E A^{5}$ e RIMA ${ }^{6}$ para a sua execução e que em muitos casos tem se colocado como um obstáculo para o desenvolvimento, quando na verdade não deve ser interpretado desta forma e sim como um ordenamento ambiental do crescimento econômico.

\section{ASPECTOS JURÍDICOS DO LICENCIAMENTO AMBIENTAL}

Com base neste contexto apresentado, legislações federais, como: a Política Nacional do Meio Ambiente (BRASIL, 1981) e seu Decreto Regulamentador (Decreto 99.274/90), a Constituição Federal de 1988, Lei Complementar 140/2011 e as Resoluções do Conselho Nacional do Meio Ambiente (CONAMA), se encarregaram de prever um instituto ou instrumento legal com o objetivo de garantir um meio ambiente equilibrado sendo de caráter preventivo, por meio do denominado licenciamento ambiental, procedimento administrativo, que visa dirimir os danos ambientais produzidos por atividades poluidoras. 0 instituto do licenciamento é um mecanismo tão importante para a proteção do meio ambiente que é denominado, também, de instrumento de comando e controle. Pois atua de forma preventiva, seleciona as atividades e impõe condicionantes de controle das licenças expedidas, com o cumprimento de prazos, inclusive de renovação.

Este caráter preventivo do licenciamento é decorrente do poder de polícia conforme destaca Granziera (2011) sendo um mecanismo de controle e restrição

4 AlA - Avaliação de Impacto Ambiental pode ser definida como uma série de procedimentos legais, institucionais e técnico-científicos, com o objetivo caracterizar e identificar impactos potenciais na instalação futura de um empreendimento, ou seja, prever a magnitude e a importância desses impactos (BITAR; ORTEGA, 1998).

5 EIA - Estudo de Impacto Ambiental também denominado de prévio, pode ser definido como um estudo que visa apresentar os impactos positivos e negativos do empreendimento sendo obrigatório de acordo com 0 art. $3^{\circ} \mathrm{da}$ Resolução CONAMA n $237 / 97$ para empreendimentos e atividades efetiva ou potencialmente causadoras de degradação ambiental.

6 RIMA - Relatório de Impacto sobre o Meio Ambiente é um resumo do EIA, com uma linguagem menos técnica tem o objetivo de apresentar as principais informações do empreendimento. No caso de audiência pública este será apresentado aos interessados. da atividade humana ao tempo que visa impedir que esta cause danos ao meio, destaca ainda os princípios da prevenção, ou seja, prevenção de danos e ainda a prevalência do interesse público sobre o privado.

0 caráter do licenciamento ambiental é preventivo ao tempo que visa atender interesse do empreendedor e proteção ambiental, seja ele pessoa física ou jurídica, de direito público ou privado, preencha os requisitos legais, sendo que poderá ser revisto a qualquer tempo. Importante fazer uma distinção inicialmente entre pessoa física e jurídica, a primeira se classifica como todo aquele sujeito de direito que possui personalidade jurídica, são os seres humanos, também denominadas de pessoas naturais. Já as pessoas jurídicas são entidades abstratas, não corpóreas com responsabilidade jurídica, capaz de direitos e obrigações ao adquirir sua personalidade jurídica, estas por sua vez, dividem-se em públicas e privadas. As pessoas jurídicas de direito público são aquelas que pertencem ao Estado brasileiro e as de direito privado são aquelas que pertencem aos particulares.

Ambas, sejam elas pessoas físicas ou jurídicas são responsáveis pelas atividades que desenvolvem, portanto estão sujeitas ao licenciamento. Espera-se que as pessoas jurídicas de direito público só iniciem determinada atividade após a devida licença, ficando para as pessoas físicas e jurídicas de direito privado a falta de licença no exercício de suas atividades. Para um melhor entendimento sobre o procedimento se faz necessário uma análise da legislação ambiental sobre a temática vigente.

O Licenciamento Ambiental está previsto como instrumento da promoção da proteção do meio ambiente e está disposto no Art. $9^{\circ}$ da Política Nacional do Meio Ambiente.

Diante desta previsão legal e com o advento da Constituição Federal de 1988, o licenciamento passou a desempenhar importante função na seara administrativa ambiental, ao passo que visa um controle de autorização de atividades efetiva ou potencialmente poluidoras por meio da expedição de licenças ambientais.

0 art. 225 da Constituição Federal trouxe a proteção do meio ambiente e um dos estudos presen- 
tes no Licenciamento Ambiental que é o Estudo Prévio de Impacto ambiental, previsto no inciso IV, parágrafo $1^{\circ}$, e ainda no $\S 2^{\circ}$.

Diante do que estas legislações preveem, foi necessário estabelecer quais atividades/empreendimentos são passíveis e obrigatórias o licenciamento ambiental, para atender tal necessidade foi redigida a Resolução 237/97 do CONAMA, em seu anexo 1 prevê um rol ${ }^{7}$ exemplificativo destas atividades sujeitas ao licenciamento ambiental. Pode-se afirmar que esta resolução tem força de lei e atualmente na legislação brasileira é a mais importante no que diz respeito ao licenciamento ambiental.

\section{AS ATIVIDADES SUJEITAS AO LICENCIAMENTO AMBIENTAL}

As Resoluções CONAMA são importantes fontes de informação no que se refere as atividades sujeitas ao licenciamento ambiental. Além da já referida Resolução 237/97, atividades descritas no Anexo 1 dessa Resolução, podem-se destacar as descritas na Resolução $n^{0} 1 / 86$, especificamente no Art. $2^{\circ}$.

0 objetivo do licenciamento ambiental é ao final de ter transcorrido o processo administrativo em um órgão ambiental competente, expedir uma licença ambiental, que poderá ocorrer ou não, conforme preceitua o Art. 10 $^{\circ}$ II, da Resolução CONAMA 237/97.

Destaque-se para a classificação das atividades que são aquelas consideradas efetiva ou potencialmente poluidoras ou aquelas que, sob qualquer forma, possam causar degradação ambiental. A discricionariedade em identificar a lesividade de tais atividades

\footnotetext{
70 Anexo 1 da Resolução CONAMA 237/97 classifica as atividades sujeitas ao licenciamento ambiental em: extração e tratamento de minerais, Indústria de produtos minerais não metálicos, Indústria metalúrgica, Indústria mecânica, Indústria de material elétrico, eletrônico e comunicações, Indústria de material de transporte, Indústria de madeira, Indústria de papel e celulose, Indústria de borracha, Indústria de couros e peles, Indústria química, Indústria de produtos de matéria plástica, Indústria têxtil, de vestuário, calçados e artefatos de tecidos, Indústria de produtos alimentares e bebidas, Indústria de fumo, Indústrias diversas, Obras civis, Serviços de utilidade, Transporte, terminais e depósitos, Turismo, Turismo, Atividades agropecuárias, Uso de recursos naturais.
}

é do órgão ambiental mediante a sua competência designada por lei, será objeto de tópico seguinte.

Para uma melhor classificação das atividades sujeitas ao licenciamento ambiental, estudos científicos oriundos de pesquisadores das ciências ambientais são utilizados como fonte, demonstrando a importância da interdisciplinaridade na proteção do meio ambiente. As atividades e empreendimentos que apresentarem a potencialidade de poluição deverão apresentar Estudo de Impacto Ambiental e Relatório de Impacto sobre o Meio Ambiente (EIA/RIMA), como prevê o art. $3^{\circ}$ da Resolução CONAMA 237/97.

Este estudo é de extrema importância para a efetividade do princípio da precaução, tendo em vista que nele deve conter todas as informações referente aos impactos ambientais positivos e negativos que a atividade ou empreendimento irá produzir. Além das medidas preventivas que serão adotadas pelo empreendimento a fim de promover o menor impacto possível.

\section{COMPETÊNCIA PARA 0 LICENCIAMENTO AMBIENTAL}

No ano de 1997 com o advento da Resolução CONAMA 237, ficara estabelecida a competência para o licenciamento no Brasil com atribuição aos entes federativos, União, Estados, Distrito Federal e Municípios. Já em 2011 a Lei Complementar 140, passou a regular as atribuições.

Com base na Constituição Federal, os entes federativos recebem atribuições desta e suas limitações quanto a sua atuação também é regulada. Já o art. 225 prevê a atuação conjunta da sociedade e do poder público na proteção ambiental. Como instrumento desta proteção o licenciamento ambiental é utilizado, visando evitar danos ambientais.

Somente com a Resolução 237/97, terminaram várias dúvidas em relação a qual ente federativo detém competência para apreciar o processo de licenciamento requerido pelo interessado. Surgiu assim, a necessidade de uma legislação mais clara e efetiva em relação a competência, pois em alguns casos, 
empreendimentos foram orientados a realizar mais do que um licenciamento ambiental. Por uma questão técnica legislativa a Resolução CONAMA 237/97, foi substituída pela Lei Complementar 140/11, pois a Constituição Federal determinava o estabelecimento das competências via Lei Complementar e não por Resolução, como havia sido feito.

Em termos práticos a Lei Complementar ratificou o que dispunha a Resolução 237/97, estabelecendo o licenciamento ambiental em nível único, pelos órgãos executores do Sistema Nacional do Meio Ambiente no Brasil (SISNAMA), com possibilidade de manifestação dos órgãos ambientais de outras instâncias, mas não de forma vinculante.

A principal regra ou requisito para o licenciamento ambiental foi mantido pela referida Lei Complementar, ou seja, o critério da abrangência do impacto, o qual se classifica em: se local, a competência é do Município; se for em mais de um município dentro do mesmo Estado, cabe ao este e se ultrapassar mais de um Estado ou País, cabe a órgão federal específico, somente em um nível.

De acordo com Costa (2012) além do critério de impacto fica estabelecido que cabe à União o licenciamento ambiental de empreendimentos e atividades nas seguintes situações: a) localizados ou desenvolvidos no mar territorial, na plataforma continental ou na zona econômica exclusiva (critério geográfico); b) localizados ou desenvolvidos em terras indígenas (critério nacional); c) localizados ou desenvolvidos em unidades de conservação instituídas pela União, exceto em áreas de Proteção Ambiental - APA (critério da dominialidade); d) de caráter militar, excetuando-se do licenciamento ambiental, nos termos de ato do Poder Executivo, aqueles previstos no preparo e emprego das Forças Armadas (critério da segurança nacional). Ainda: e) relativos à energia nuclear ou materiais radioativos (critério da segurança nacional); f) que atendam tipologia estabelecida por ato do Poder Executivo, a partir de proposição da Comissão Tripartite Nacional (formada por representantes dos Poderes Executivos da União, dos Estados, do Distrito Federal e dos Municípios, com o objetivo de fomentar a gestão ambiental compartiIhada e descentralizada entre os entes federativos.
Acrescenta Costa (2012) no caso de empreendimentos situadas na zona costeira com localização da faixa terrestre e marítima o licenciamento somente será federal, nos casos indicados expressamente pelo executivo, a partir de proposta de tipologia da Comissão Tripartite Nacional (art.7º parágrafo único, da LC 140/2011).

A LC 140/2011 estabelece que nos casos de licenciamento de competência federal, caberá ao Instituto Brasileiro do Meio Ambiente e dos Recursos Naturais Renováveis (IBAMA) esta função, condicionando-se, em alguns casos, à autorização ou parecer de outros órgãos mais específicos, tais como casos de empreendimentos localizados ou desenvolvidos em unidades de conservação federal, onde há participação obrigatória da ICMBio e também relacionados à energia nuclear ou a materiais radioativos, sujeitos à parecer da Comissão Nacional de energia Nuclear - CNEN (art. $7^{0}$, XV, “g”, da LC140/2011).

Continua Costa (2012), para os Estados foi adotado o critério da competência licenciatória residual (pode licenciar aquilo que não for da atribuição da União e dos Municípios, o que redunda no critério da abrangência do impacto), sendo-lhe expressamente estabelecida, assim como para os municípios, a atribuição para licenciamento de atividades ou empreendimentos em unidades de conservação estaduais ou municipais respectivamente, com exceção de área de proteção ambiental - APA (arts. $8^{\circ}$, XIV e XV, “b”).

Os casos de conflitos de competência já foram amplamente discutidos nos tribunais brasileiros e ainda assim continua o debate acerca do tema.

\section{IMPASSE JURÍDICO SOBRE A NECESSIDADE DE LICENCIAMENTO E A COMPETÊNCIA AMBIENTAL PARA AS ESTAÇÕES RÁDIO BASE -ERB ${ }^{8}$}

Uma das atividades que são objeto de discussão no meio científico, acadêmico e judicial, são as cha-

8 Estação Rádio Base (ERB) ou “Cell site” é a denominação dada em um sistema de telefonia celular para a Estação Fixa com que os terminais móveis se comunicam. 
madas antenas rádio base e seus possíveis danos à saúde humana. Estudos científicos apresentam relação de aumento de câncer em pessoas que residem próximas a antenas instaladas a pequenas distâncias de suas residências. Existem, também, estudos que apresentam resultados contrários a estas informações, afirmando que as antenas emitem baixos níveis de radiação e não causam malefício algum.

Em algumas cidades do país, o Ministério Público e órgãos ambientais impetraram ações judiciais, requerendo a retirada das antenas das áreas residenciais. As empresas telefônicas reagiram e alegaram que 0 serviço não causa malefício algum, cite os exemplos e as decisões de Aracaju-SE e posteriormente entendimento do Superior Tribunal de Justiça sobre o caso em apreço:

Análise, Comentário n 1 - VIVO x EMPRESA MUNICIPAL DE OBRAS E URBANIZACAO - EMURB, Acórdão n²01620024, Tribunal de Justiça de Sergipe, 2016

Trata-se de Apelação Cível interposta pela VIVO (apelante) em razão de sentença oriunda da Ação de Obrigação de Fazer ajuizada pela Empresa Municipal de Obras e Urbanização de Aracaju (EMURB), com o objetivo de compelir a Vivo S/A (Telefônica Brasil S/A) a regularizar o processo de funcionamento, (2675/2011), da Estação Rádio Base (ERB) situada à Rua Tenente Cleto Campelo, $\mathrm{s} / \mathrm{n}$, Bairro 18 do Forte, em conformidade com a Lei Municipal $n^{0} 3.858 / 2010$, trazendo os documentos exigidos pela legislação municipal, concluindo o processo de licenciamento no prazo máximo de 30 dias, sob pena de suspensão da atividade da ERB9 e de retirada do equipamento.

Em sede de apelação a apelante suscitou as seguintes legislações: Lei Municipal no 3.858/201010 e Lei Municipal n 4.604/201411. Destacando que

9 Estação Rádio Base (ERB) é a denominação dada a um sistema de telefonia celular para a Estação Fixa com que os terminais móveis se comunicam, permitindo chamadas entre eles e os terminais de telefones fixos comuns. 10 Lei Municipal $n^{\circ} 3.858 / 10$, dispõe sobre a instalação de Estações Rádio bases, equipamentos afins de rádio, televisão, telefonia, telecomunicações em geral no município de Aracaju e dá outras providências.

11 Lei Municipal $n^{\circ} 4.604 / 14$, que dispõe sobre o licenciamento para instalação de estações rádio-base, fontes transmissoras e equipamentos afins de radiocomunicação, televisão, telefonia e telecomunicações em geral. ambas são inconstitucionais, portanto não caberia a Apelada o procedimento do licenciamento ambiental. Cabe neste ponto um estudo aprofundado das competências legislativas no licenciamento ambiental.

Destaque-se ainda para a alegação da apelante que a atividade não é poluidora e a responsável pelo devido licenciamento ambiental é a Anatel.

No relatório a Desa. Elvira Maria de Almeida Silva apresenta aspectos relevantes do processo de $1^{\circ} \mathrm{grau}$ que devem ser analisados de forma aprofundada com base na doutrina e jurisprudência pátrias, eis trecho do relatório da jurisprudência suscitada:

\begin{abstract}
Inclusive, quanto ao aspecto também mencionado pela requerida de inexigência da licença ambiental, porque não exerce, supostamente, atividade poluidora, tenho que, primeiramente, essa prova era sua, de que as ERBs não poluem. E verificando todo o processo, não encontrei prova alguma nesse sentido, nenhum estudo técnico, ou mesmo uma perícia particular ${ }^{12}$.
\end{abstract}

Ao Iniciar com o primeiro aspecto suscitado pela desembargadora, é em relação a prova, obviamente que a apelante não iria produzir prova contra si, portanto não juntou aos autos estudo técnico, perícia particular e outros, a fim de demonstrar que não causam danos ambientais, o que incide sobre a saúde humana e animal, além de ser um descumprimento de ordem legal, para o Direito Ambiental e para as Ciências Ambientais (estudo dos danos) não foi questionado, em sede de Apelação. Porém insta salientar que o dano ambiental indireto pode ser o mais perverso, ou pode-se insurgir uma nova categoria de dano, denominado de oculto, tendo como seu suporte legislativo e doutrinário o princípio da precaução, pois na falta de certeza de que a atividade não seja danosa, ela deve ser evitada.

Estudos recentes indicam que antenas rádio base de telefonia celular podem causar câncer e outras doenças, conforme aponta Vieira (2017), os sintomas

12http://www.tjse.jus.br/tjnet/jurisprudencia/relatorio.wsp?tmp_ numprocesso $=201600718208 \mathrm{dtmp}$ _numacordao $=201620024 \mathrm{Etmp}$. expressao=aus $\%$ C $3 \%$ AAncia $\% 20$ de $\% 20$ licenciamento $\% 20$ ambiental 
são similares aos da incidência dos celulares ${ }^{13}$. Além do desenvolvimento do DNA cancerígeno, a população pode apresentar dores de cabeça, fadiga, insônia, depressão, infertilidade, epilepsia, púrpura, leucemia, aborto espontâneo e falta de produção de leites em lactantes, além de outros sintomas.

O dano como demonstrado existe, é real e deve ser evitado, medidas assecuratórias devem ser tomadas, pois soluções para o problema existem, como salienta Vieira e Kiszka (2017) a ideia seria retirar as torres perto de escolas, hospitais e residências e as colocarem em praças, em que o tempo de permanência das pessoas é menor. Como outra solução, os autores indicam a inserção das High Altitude Plataform (HAP), que são balões que se hospedam no céu, onde o campo magnético não consegue chegar até as pessoas e 0 sinal da rede de telecomunicação até melhora.

Um dos maiores problemas encontrados neste caso é a preocupação em analisar a lei no aspecto jurídico e puramente técnico no que tange a chamada competência para exigir ou não licenciamento de órgão municipal ou federal, enquanto que o aspecto ambiental não é enfatizado. A questão é anterior a quem vai exigir o documento administrativo, ela precede a própria discussão, evidenciando que a atividade deve apresentar estudo técnico que comprove a sua distância de residências, escolas, hospitais, animais, entre outros.

Em relação ao estudo elaborado por técnicos especializados, não apresentados ao processo em discussão, é mais um motivo para a paralização das atividades até a regularização das medidas assecuratórias ao meio ambiente.

Neste aspecto, a referida Desembargadora, apresenta a justificativa de que as provas que seriam apresentadas (e não foram) no decorrer do processo de $1^{\circ} \mathrm{grau}$, iriam fundamentar decisão a posteriori no pedido de antecipação de tutela da apelada que fora negado, segue trecho da exordial:

13 Maiores informações consultar o endereço eletrônico: http://www.comunica.ufu.br/noticia/2017/06/pesquisa-indica-que-radiacao-de-torres-e-celulares-pode-causar-cancer
[...]São essas as bases da insurgência recursal, as quais, a meu ver, não comportam provimento, a despeito de, no agravo de instrumento que julguei, como relatora, referente ao pedido de modificação da tutela antecipada concedida pelo juízo monocrático, haver dado provimento ao recurso aviado pela telefônica, com fundamento na possível revogação da lei 3.858/2010 pela lei 4.604/2014.

Porém, como se tratou de análise perfunctória, própria daquele momento processual, achei melhor deixar que o processo tramitasse com colheita de mais provas, uma vez que a estação rádio já funcionava no local desde $2009^{14}$.

Ainda neste aspecto, insta salientar, que decisão sobre a temática já foi debatida e julgada no Distrito Federal como destacam Vieira e Kiszka (2017, on-line):

No Distrito Federal, por exemplo, desde 2004, se discute a proibição de instalação de antenas de celular em terrenos próximos às escolas. Em julho do ano passado, o Ministério Público do Distrito Federal e Territórios alegou que as antenas colocam em risco a saúde das crianças e recomendou a retirada de 31 antenas pelas empresas de telecomunicações ${ }^{15}$.

Portanto já existem precedentes nos tribunais pátrios a respeito da temática, o que corrobora na decisão de $1^{\circ}$ e $2^{\circ}$ grau do TJ de Sergipe.

No momento atual a sentença de $1^{\circ} \mathrm{grau}$ não foi executada, tendo em vista que os apelantes ingressaram com Agravo em Recurso Especial e Agravo em Recurso Extraordinário, remetidos à apreciação do STJ e posteriormente ao STF.

A seguir trata-se de Recurso Especial analisado pelo STJ e posterior decisão sobre o caso:

Análise, Comentário nº 2 - Telefônica Brasil S. A. x Município de Piracicaba, REsp 1660410, Superior Tribunal de Justiça-STJ, 2017.

TORRE RETRANSMISSORA DE TELEFONIA MÓVEL. NECESSIDADE DE OBSERVÂNCIA DA LEGISLAÇÃO

\footnotetext{
14http://www.tjse.jus.br/tjnet/jurisprudencia/relatorio.wsp?tmp_ numprocesso $=201600718208 \& \mathrm{tmp}$.numacordao $=201620024 \mathrm{\& tmp}$. expressao=aus\%C3\%AAncia\%20de\%20licenciamento\%20ambiental).

15 Maiores informações consultar o endereço eletrônico: http://www.comunica.ufu.br/noticia/2017/06/pesquisa-indica-que-radiacao-de-torres-e-celulares-pode-causar-cancer
} 
LOCAL. "A retirada das estações rádio base em desacordo com as posturas locais não invade a competência legislativa da União" (RMS 22.885-STJ Min. FRANCISCO FALCÃO), em consonância com o que dispõe a art. 74 da Lei n 9.472, de 1997: “A concessão, permissão ou autorização de serviço de telecomunicações não isenta a prestadora do atendimento às normas de engenharia e às leis municipais, estaduais ou do Distrito Federal relativas à construção civil e à instalação de cabos e equipamentos em logradouros públicos".

Não provimento do recurso. Os Embargos de Declaração foram rejeitados. A recorrente alega violação dos arts. 128, 460, 535 do CPC/1973; 10, 19, IV, X, XII, da Lei $9.472 / 1997$. Assevera que há negativa de prestação jurisdicional. Defende que as normas municipais usurparam a competência conferida à ANATEL, ao interferirem na regulação das telecomunicações. Aduz ser competência exclusiva da União, pela ANATEL, regular a disciplina, fiscalização, execução e uso dos serviços e da implantação e funcionamento das redes de telecomunicações. Ressalta que as regras de funcionamento da estação de radiobase são matérias relacionadas a telecomunicações. Alega que a determinação de retirada da estação radiobase é extra petita, porque o pedido seria de regularização da estação quanto aos equipamentos adicionais e não para sua retirada em razão de sua localização em bairro residencial. Defende que o art. 10, VII, da Lei 7.783/1989 foi ofendido porque o serviço não poderia deixar de ser prestado por ser essencial.

Irresignada com a decisão do Acórdão que decidiu por manter a decisão de retirada dos equipamentos de área residencial, a empresa Telefônica recorreu ao STJ com o intuito de manter as mesmas, alegando que a competência para legislar sobre a atividade é da União/ANATEL e que lei municipal sobre o tema não deve prosperar. Complementa ainda em seu recurso que a retirada das antenas afetaria o serviço prestado considerado por estas como essencial.

Pois bem, até o início dos anos 1990 no Brasil não existiam celulares, tornando-se cada vez mais acessível à população somente a partir dos anos 2000. Atualmente no Brasil existem cerca de 236 milhões de celulares ativos, isto representa o sexto país em número de linhas telefônicas no mundo, o que representa um local de bastante interesse para as empresas de telefonia móvel.

Aliás este é um fato que deve ser levado em consideração, o quanto as empresas lucram vendendo celular, os custos com a manutenção, seja com contas pré e pós-pagas, além de exploração de acessórios, fica claro o interesse econômico na exploração da atividade, o investimento é alto, o que significa que mudanças geram custos na qual as empresas não querem suportar.

Alguns países europeus e Estados Unidos, com vistas ao princípio da precaução, tem exigido distância mínima para instalação das antenas Erb’s. A distância mínima no Brasil está prevista na Resolução n0303/2002 da ANATEL, especificamente no Art. $5^{\circ}$ a seguir:

\begin{abstract}
Art. $5^{\circ}$ As Tabelas I e II apresentam, respectivamente, os limites para exposição ocupacional e da população em geral a CEMRF, na faixa de radio freqüências entre $9 \mathrm{kHz}$ e $300 \mathrm{GHz}$.

Parágrafo único. Os limites de exposição indicados no caput deste artigo são estabelecidos em termos de campo elétrico, campo magnético e densidade de potência da onda plana equivalente e foram obtidos a partir das Restrições Básicas apresentadas nas Tabelas V e VI. Estes limites são equivalentes aos Níveis de Referência indicados nas diretrizes da ICNIRP e foram estabelecidos em termos de grandezas que podem ser mais facilmente medidas ou calculadas que as Restrições Básicas.
\end{abstract}

De acordo com a ANATEL o número de antenas instaladas no Brasil vem aumentando ano a ano, o que demonstra a necessidade de uma maior fiscalização em relação ao cumprimento das normas jurídicas com o objetivo de se evitar danos. Segue uma tabela com o número de antenas instaladas no Brasil entre 2016 a 2018 por operadora.

\title{
Estações Rádio Base no Brasil por Operadora
}

$\begin{array}{cccc}\begin{array}{c}\text { Operadora } \\ \text { Vivo }\end{array} & \mathbf{2 0 1 6} & \mathbf{2 0 1 7} & \text { Jan/18 } \\ & 20.662 & 22.471 & 22.497 \\ \text { TIM } & 20.092 & 21.514 & 21.612 \\ \text { Claro } & 16.228 & 18.722 & 18.722 \\ \text { Oi } & 17.562 & 18.148 & 18.148\end{array}$




\section{Operadora}

Nextel

2016

2017

Jan/18

7.095

Algar

7.475

7.071

701

706

Sercomtel

49

54

55

\section{Total}

82.747

88.681

88.835

Fonte: http://www.teleco.com.br/erb.asp

Fatos e dados apresentados demonstram a necessidade de uma maior fiscalização dos órgãos ambientais nas instalações de antenas ERb e na sua manutenção.

\section{CONCLUSÃO}

Percebe-se diante da problemática descrita, que os Estudos Ambientais são fundamentais para a tomada de decisão. Estes, devem ser apresentados na fase inicial do pedido de licenciamento ambiental, a fim de se evitar danos ambientais.

O que mais se evidencia nas decisões dos tribunais pesquisados é a prevalência da necessidade econômica da manutenção das atividades poluidoras, causadoras de impacto (até mesmo incertas em relação ao seu impacto) em detrimento ao meio ambiente.

Questões técnicas jurídicas não devem ser um empecilho para a proteção ambiental, pois a lei que protege não deve gerar dúvidas na sua aplicação e abrir caminhos para a vulnerabilidade.

Até o presente momento o único local habitável para os seres humanos é o planeta Terra, sendo necessária uma mudança nos valores e uma consciência ambiental voltada para a reutilização. A sociedade encaminha-se para a fase das escolhas e prioridades, na verdade esta fase já chegou, porém na prática pouco vislumbra-se em relação ao resultado. 0 que se vê é o capital realizando as escolhas e ditando as regras. As consequências todos já estão passando.

\section{REFERÊNCIAS}

ARAÚJO, Sara Carneiro. Competência em matéria de licenciamento ambiental: do conflito à solução? R. Fac. Dir., Fortaleza, v.34, n.1, p.499-538, jan-jun. 2013.

BRASIL. Lei 6.938/81. Disponivel em: <http://www. planalto.gov.br/ccivil_03/leis/L6938compilada.htm>. Acesso em: 30 jan. 2018.

BRASIL. Ministério do Meio Ambiente. Resolução CONAMA nº 01/86. Disponível em: <http://www.mma. gov.br/port/conama/res/res86/res0186.html>. Acesso em: 30 jan. 2018.

BRASIL. Constituição Federal de 1988. Disponível em: <http://www.planalto.gov.br/ccivil_03/constituicao/ ConstituicaoCompilado.htm>. Acesso em: 31 jan. 2018.

BRASIL. Ministério do Meio Ambiente. Resolução CONAMA n0 237/97. Disponível em: <http://www.mma. gov.br/port/conama/res/res97/res23797.html> Acesso em: 30 jan. 2018.

BRASIL. Lei 9.605/98. Disponível em: <http://www. planalto.gov.br/ccivil_03/leis/l9605.htm>.

Acesso em: 30 jan. 2018.

BRASIL. Decreto 6.514/08. Disponível em: <http:// www.planalto.gov.br/ccivil_03/_ato2007-010/2008/ decreto/D6514.htm>. Acesso em: 29 jan. 2018.

BRASIL. Lei Complementar n⿳0 140/2011. Disponível em: <http://www.planalto.gov.br/ccivil_03/leis/lcp/ Lcp140.htm>. Acesso em: 30 jan. 2018.

COSTA, Sandro Luis da; Soares, Maria José Nascimento; PESSOA, Flávia Moreira Guimarães. Panorama do licenciamento ambiental no Brasil. In: BITENCOURT, Daniela Venceslau; ALMEIDA, Ronise Nascimento de; OMENA, Maria Luiza. (Org.). Perspectivas da sustentabilidade. São Cristóvão: UFS, v.1, p.179-200, 2012. 
FIORILLO, Celso Antonio Pacheco; MORITA, Dione Mari; FERREIRA, Paulo. Licenciamento ambiental. São Paulo: Saraiva, 2015.

GRANZIERA, Maria Luiza Machado. Direito ambiental. São Paulo: Atlas, 2011.

SARLET, Ingo Wolfgang; FENSTERSIFER, Tiago. Princípios de direito ambiental. São Paulo: Saraiva, 2014.
TELECO Inteligência em Comunicações. Estações rádio base no Brasil por operadora. Disponível em: <http://www.teleco.com.br/tutoriais/tutorialerb/pagina_1.asp>. Acesso em: 30 jan. 2018.

VITAL, Talita. Pesquisa indica que radiação de torres e celulares pode causar câncer. Comunica.ufu.br. 1 jun. 2017. Disponível em: < http://www.comunica. ufu.br/noticia/2017/06/pesquisa-indica-que-radiacao-de-torres-e-celulares-pode-causar-cancer>. Acesso em: 30 jan. 2018.8 
